\title{
LA SUBTRIBU STANHOPEINAE: SUS NOTABLES MECANISMOS DE POLINIZACIÓN, LA QUÍMICA DE SUS AROMAS FLORALES E IMPLICACIONES EN SISTEMÁTICA Y TAXONOMÍA
}

\author{
GÜNTER GERLACH \\ Botanischer Garten München-Nymphenburg, Menzinger Str. 65, 80638 München, Alemania \\ gerlach@botanik.biologie.uni-muenchen.de
}

Las flores de las especies de la subtribu Stanhopeinae pertenecen a las más fascinantes y extravagantes de todas las orquídeas. No son de las más bellas, pero debido a su polinización tan particular a veces han creado flores bizarras con mecanismos de polinización muy extraños. Charles Darwin, el fundador de la teoría de la evolución de las especies en el siglo antepasado, se dedicó mucho a la polinización de flores y supo también de la polinización de orquídeas por abejas euglósidas, pero sin saber qué beneficios sacan estas abejas tan particulares de las flores. Con su trabajo pionero el biólogo Stefan Vogel en los años 60 del siglo 20 descubrió el verdadero atrayente de estas flores. Se trata de perfumes, sustancias químicas que son colectadas por los machos euglósidos.

Únicamente en el neotrópico se originó el síndrome de flores con perfumes. Se trata de plantas que ofrecen en abundancia perfumes en su flores, y son solamente los aromas florales los que sirven para atraer y recompensar a los polinizadores. Es interesante que aunque los machos juegan un papel importante en la polinización, normalmente las hembras son más importantes en este proceso, porque son más constantes en su visita de flores y además no colectan solamente para sí mismas, sino también para sus crías. Al lado de algunas orquídeas [en total: Stanhopeinae, Coeliopsidinae, Catasetinae, en parte: Lycastinae (Anguloa), Oncidiinae (Notylia) y Zygopetalinae (Dichaea)] las familias Solanaceae (Solanum grupo Cyphomandra), Euphorbiaceae (algunas especies de Dalechampia), Gesneriaceae (Gloxinia perennis y algunas otras) y Araceae (Spathiphyllum, algunas especies de Anthurium) están incluidas en este síndrome floral de perfumes. Todas las plantas mencionadas son polinizadas exclusivamente por machos euglósidos que buscan y recolectan perfumes en estas flores. Hasta ahora no sabemos para qué los machos colectan y guardan estos perfumes; puesto que no sirven para nutrición ni protección tienen que tener algo que ver con los ritos en la vida sexual de los insectos.

La manera de colectar estos perfumes es siempre muy parecida. El macho se acerca a la fuente del aroma, el osmóforo; normalmente se posa sobre el labelo y empieza a colectar con sus patas delanteras las sustancias responsables del aroma. En la mayoría de casos son líquidos; en algunas especies en forma cristalina. Si son sólidos, el macho los disuelve primero con secreciones de sus glándulas labiales. Con pelos largos y densos en las patas delanteras, el macho absorbe el líquido presente en el labelo. Si este órgano está saturado de los componentes aromáticos, la abeja sale de la flor para transferir los aromas con la ayuda de las patas medias a cavidades que se encuentran en las patas traseras. En el interior de estas cavidades las sustancias pueden ser guardadas por mucho tiempo.

Normalmente las orquídeas son fáciles de hibridar artificialmente: hasta híbridos entre cinco géneros son conocidos, pero híbridos naturales entre especies de un género de Stanhopeinae son raros en la naturaleza. Nunca se han hallado híbridos entre géneros en la selva, aunque son fáciles de obtener artificialmente. Una barrera mecánica evita la hibridación en los géneros. Robert Dressler se dedicó mucho tiempo al estudio de la polinización de orquídeas pertenecientes al síndrome floral de perfumes. Él describió las diversas formas en que distintos géneros de orquídeas pegan los polinarios a diferentes partes del cuerpo de los polinizadores.

Los machos no colectan cualquier perfume, sino sustancias particulares. Fue Calaway Dodson quien 

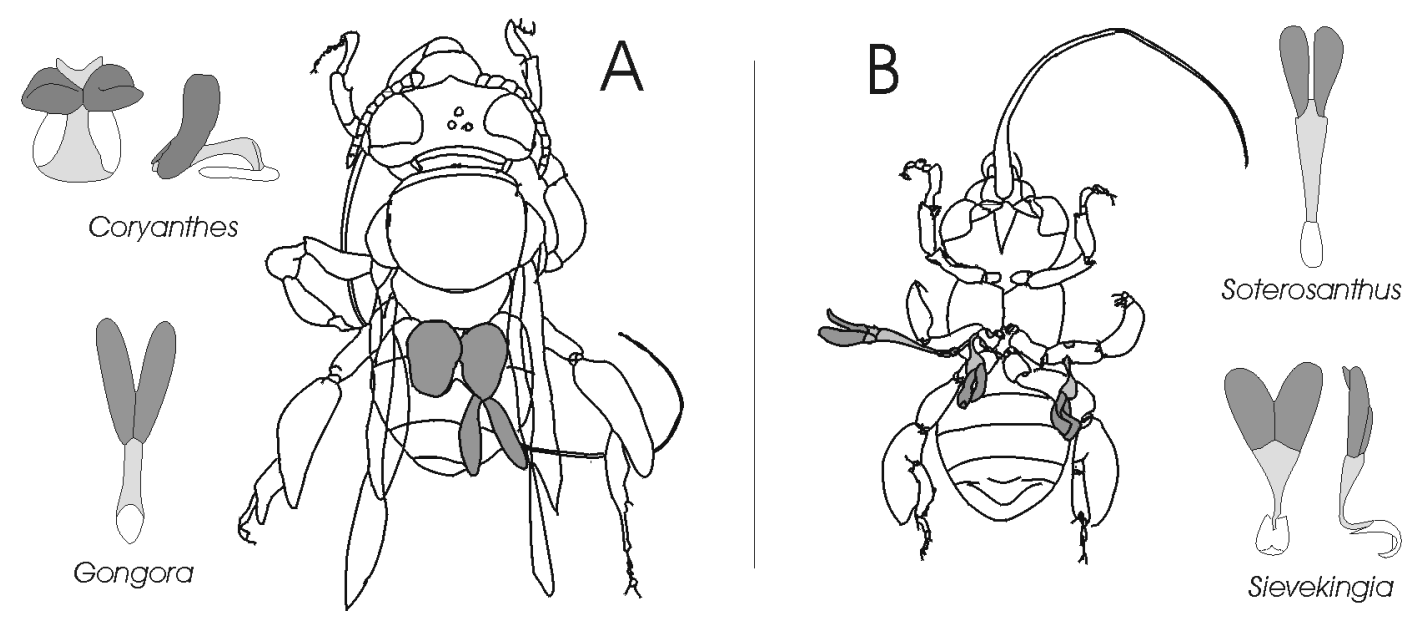

Fig. 1. A - Euglossa imperialis con polinarios de Gongora sp. y Coryanthes mastersiana; abeja vista desde arriba. B - Euglossa crassipunctata con polinarios de Soterosanthus shepheardii (enroscados, así se encuentran debajo del cuerpo) y Sievekingia sp. (tieso, así orientado hacia afuera del cuerpo); abeja vista desde abajo. Ilustración: Corina Gerlach.

sentó las bases de la investigación sobre orquídeas polinizadas por machos euglósidos que buscan y recolectan perfume en las flores. La barrera entre las especies de un género generalmente es, entonces, química. Finalmente fueron Mark Whitten y Norris Williams quienes establecieron el análisis de los aromas de las flores por cromatografía de gases. Hoy día existen muchas investigaciones respecto a la composición química de varias especies de géneros con el síndrome de perfumes (tal vez la mitad sin publicar), pero todavía falta información de aproximadamente una tercera parte de las Stanhopeinae. Se puede decir que el aroma floral da más información sobre la integridad de una especie que su morfología. Para la taxonomía, el análisis de aromas florales no es muy útil, porque casi todas las descripciones antiguas carecen de descripciones de aromas y en los herbarios éstos no se conservan. Además, nosotros no estamos entrenados para distinguir los aromas y entender sus descripciones. Por otro lado, la composición química es muy útil para caracterizar una especie en las Stanhopeinae (pero este método no se puede aplicar a todas las orquídeas!) y los resultados de esta investigación pueden ser usados en su taxonomía (quimiotaxonomía).

Raramente se encuentran en colecciones euglósidos que tienen pegados polinarios de dos géneros de Stanhopeinae. De la costa Pacífica de Colombia tengo un ejemplar que tiene un polinario de Coryanthes y otro de Gongora (Fig. 1 A). Así, este macho fue atraído por el aroma de ambas plantas. Puede ser que ambas tienen el mismo aroma, un fenómeno conocido en muchos géneros de las Stanhopeinae. Hemos detectado algunos patrones en la composición química del aroma floral que se repiten en diferentes géneros, pero nunca entre las especies de un género. De todos modos, este macho visitó la segunda orquídea sin perder un polinio en el estigma. Eso muestra muy bien cuán efectiva es la barrera entre los géneros, que funciona como una llave en la cerradura.

De la misma región de Colombia vi abejas con polinarios de los géneros Soterosanthus y Sievekingia (Fig. $1 \mathrm{~B})$. Ambos géneros adhieren los polinarios a las patas del polinizador. Lo que me extrañaba era que solamente Euglossa crassipunctata llevaba estos polinarios. El colmo fue que un día un estudiante me trajo una abeja con polinarios de ambos géneros. ¿Cómo puede ser que dos géneros de orquídeas usen la misma parte del cuerpo del polinizador sin que ocurra híbridación? La explicación es la siguente: en Sievekingia el estípite se encorva un poco para que los polinios se acomoden después debajo del cuerpo de la abeja, mientras que en Soterosanthus el estípite permanece recto, orientando los polinios hacia fuera del cuerpo de la abeja. Lo curioso en esta historia es que el género 
monotípico Soterosanthus primero fue descrito como Sievekingia, pero hoy día sabemos que no tiene nada que ver con la última.

Las respuestas que da la biología de polinización a la filogenia y a la sistemática no son muy valiosas. Si dijésemos, por ejemplo, que la evolución de un viscidio en forma de garfio ocurrió en una forma ancestral (carácter monofilético), la investigación molecular moderna nos muestra todo lo contrario. Existen cuatro géneros de las Stanhopeinae que tienen viscidios en forma de garfio (Trevoria, Sievekingia, Soterosanthus y Cirrhaea), adaptados a pegar sus polinarios en patas de abejas. Según Whitten et al. (2000) existen 6 grupos naturales en la subtribu. Es muy interesante que los cuatro géneros mencionados, se dispersaron en 4 de estos 6 grupos, mostrando que el viscidio en garfio no tiene ningún significado para la filogenia. La presión evolutiva aquí es tan fuerte que no sirve como carácter para la investigación de la filogenia. Los caracteres vegetativos de las plantas son más útiles, porque se han preservado más. Por otro lado, la investigación de la polinización de las Stanhopeinae, integrando el conocimiento del aroma floral y del polinizador, nos muestra claramente cuándo se trata de una especie y cuándo no. Ojalá que, finalmente, con la ayuda del análisis del aroma floral y el conocimiento de la biología de la polinización podamos resolver los problemas de géneros como Gongora y Stanhopea. Muchas de sus especies son muy difíciles de distinguir y hasta hoy no son claramente entendidas. Sin embargo, cada vez con más amplios conocimientos y la contribución de muchas personas involucradas en estas investigaciones, el nudo gorgónico se disuelve poquito a poco.

\section{REFERENCIAS}

Dodson, C.H. 1970. The Role of the Chemical Attractants in Orchid Pollination. In: Biochemical Coevolution, K.L. Chambers, ed. Oregon State University Press, Corvalis 83-107.

Dressler, R.L. 1968. Observations on Orchids and Euglossine Bees in Panama and Costa Rica. Rev. Biol. Trop. 15(1): 143-183.

Gerlach, G. 1999. Sievekingia y Soterosanthus: parientes, pero diferentes. Sievekingia and Soterosanthus: related but different. Orquideología 21(2): 214-227.

Gerlach, G. 1999. 80. Subtribus: Stanhopeinae. In: Schlechter: Die Orchideen III / A, Berlin 2315-2435.

Vogel, S. 1963. Das sexuelle Anlockungsprinzip der Catasetinen- und Stanhopeen-Blüten und die wahre Funktion ihres sogenannten Futtergewebes. Oesterr. Bot. Z. 100: 308-337.

Williams, N.H. \& Whitten, W.M. 1983. Orchid Floral Fragrances and the Male Euglossine Bees: methods and advances. Biol. Bull. 164: 355-395.

Whitten, W.M. \& Williams, N.H. 1992. Floral Fragrances of Stanhopea (Orchidaceae). Lindleyana 7(3): 130-153.

Whitten, W.M., Williams, N.H. \& Chase, M.W. 2000. Subtribal and Generic Relationships of Maxillarieae (Orchidaceae) with Emphasis on Stanhopeinae: Combined Molecular Evidence. Amer. J. Bot. 87(12): 1842-1856.

Günter Gerlach es curador del Jardín Botánico de Múnich en Alemania, donde, aparte de otras colecciones de plantas, él es responsable de la colección de orquídeas. Él empezó como jardinero de orquídeas en el Jardín Botánico de Heidelberg (Alemania), donde se graduó estudiando orquídeas. Él ha publicado varios artículos sobre plantas neotropicales, especialmente orquídeas. Su monografía sobre el género Coryanthes es bien conocida. Actualmente se dedica más al estudio de la composición de aromas florales de Stanhopeinae y otras plantas que exhiben el síndrome de flores con perfume y analiza las implicaciones de este fenómeno en la sistemática y la taxonomía. 